\title{
Doctor... Am I going to die? A personal opinion regarding overtreatment in medicine
}

\author{
Guillermo J. Ruiz-Argüelles* and Guillermo J. Ruiz-Delgado \\ Centro de Hematología y Medicina Interna de Puebla, Clínica Ruiz, Puebla, Mexico
}

Physicians dealing with aggressive diseases are frequently asked: "Doctor...am I going to die?" This question is relatively frequent in the clinical practice of hematology, oncology, nephrology, cardiology, and other specialties dealing with very sick or infirm persons. Every time a patient makes us this question, we always respond: "Yes.... you are going to die..... and I am also going to die, and your accompanying person is also going to die....." The question should be... "When and how am I going to die,"...... and the answer could be:...... "Nobody knows when you are going to die: however, you must understand that my job, now that you have asked me to participate in the care of your health, is to keep you alive the longest time in the best possible conditions."

People wrongly think that we physicians fight against death; death will always reach all of us sooner or later. For us physicians, the key seems to provide the patient with the longest survival in the best possible conditions. The best possible conditions include physical and economic, moral, and familial.

Along with our life as physicians dealing with patients who ask this question, we have encountered several doctors who clearly ignore the statements mentioned above:

a.Physicians who engage in "therapeutic ferocity" or "therapeutic furor." Ignoring the patients' quality of life, they indicate treatments devoted only to prolong the agony of persons; these individuals are located most commonly in intensive care units and may damage a dignified death. Hospitals should be places to recover their health while not places to die.

b. Physicians who indicate novel drugs, very frequently expensive ones, become key opinion leaders or, even worse, obtain personal rewards, such as ensuring their attendance to meetings, supported by the pharmaceutical industry. These persons are usually young and pursue both recognition and rapid economic success; they are experts in findings indications for sophisticated treatments even in cases who need no treatment at all, thus leading into overtreatment ${ }^{1-4}$. Waste in healthcare is increasingly being recognized as a cause of patient harm and excess costs. In 2010, the Institute of Medicine called attention to the problem, suggesting that unnecessary services are the largest contributor to waste in the United States ${ }^{4}$. By employing the novel and very frequently expensive drugs, treatments may prolong the patients' lives by days or weeks, commonly inducing financial toxicity to patients and their families. These persons can be easily found in "speaker-training courses," "advisory boards," "expert summits," etc. ${ }^{5}$

c. Physicians who insist on admitting patients to hospitals. As a result of the medical community's current interactions with hospitals, a substantial number of doctors are obliged to admit patients into hospitals

\section{Correspondence:}

*Guillermo J. Ruiz-Argüelles

E-mail: gruiz1@ clinicaruiz.com
Date of reception: 19-10-2020

Date of acceptance: 03-11-2020 DOI: 10.24875/RMU.M20000048
Available online: $24-12-2020$

Medicina Universitaria. 2020;22(4):149-150 www.medicinauniversitaria.org

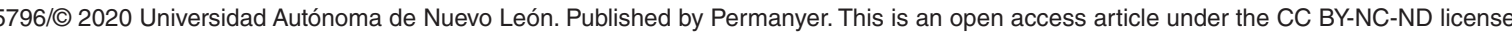
(http://creativecommons.org/licenses/by-nc-nd/4.0/). 
despite the fact that they can be treated as outpatients. Well-known cases of an inverse relation between the number of hospital admissions indicated by physicians and the cost of their medical offices' rent support this notion. On the other hand, the unnecessary admissions of patients to the hospital increases their risk of developing several complications such as nosocomial infections; hospital admissions also lead to financial toxicities and damage to the patients' well-being, which should always include their economic stability ${ }^{6}$. These physicians are located mainly in hospitals with adjacent medical offices; they tour around emergency rooms and enjoy outstanding privileges in hospitals.

d. Physicians overtreating patients. The use of excessive treatments or unnecessary therapy in special group of patients is considered overtreatment. According to the National Cancer Institute of the U.S.A., the definition is "treatment of cancer that would have gone away on its own or never caused any symptoms. These are usually found on a screening test and may lead to problems and harmful side effects from cancer therapies that are not needed." Overtreatment could happen in any patient, from the $1^{\text {st }}$ years of life to the last days. In an article from Japan, we found a clear example of this asseveration. They described older men's characteristics with prostate cancer and relative survival according to tumor stage and grade. Their findings indicate that at least $58.3 \%$ of older men with localized prostate cancer were potentially overtreated ${ }^{3}$.

We strongly feel that physicians should decide the use of drugs or treatments and the admission of patients into hospitals. This always after knowing in detail the cost-benefit ratio of these actions and considering only the comprehensive well-being of persons ${ }^{7}$, which ideally should include their physical condition and their economic, familial, and moral aspects; every patient has the right to a dignified death.If other reasons drive physicians' therapeutic actions - such as those mentioned above - they will never be able to provide an adequate and sincere response to the question which entitles this typescript. "Doctor: am I going to die ?..... yes, my friend, we are all going to die......"

\section{Conflicts of interest}

The authors declare no conflicts of interest.

\section{References}

1. Cruz-Mora A, Murrieta-Alvarez I, Olivares-Gazca JC, León-Peña A, Cantero-Fortiz Y, García-Navarrete YI, et al. Up to half of patients diagnosed with chronic lymphocytic leukemia in México may not require treatment. Hematology. 2020;25:156-9.

2. Murrieta-Âlvarez I, Steensma DP, Olivares-Gazca JC, Olivares-Gazca M, León-Peña A, Cantero-Fortiz Y, et al. Treatment of persons with multiple myeloma in underprivileged circumstances: real-world data from a single institution. Acta Haematol. 2020. doi: 10.1159/000505606. Epub ahead of print.

3. Masaoka H, Ito H, Yokomizo A, Eto M, Matsuo K. Potential overtreatment among men aged 80 years and older with localized prostate cancer in Japan. Cancer Sci. 2017:108:1673-80.

4. Lyu H, Xu T, Brotman D, Mayer-Blackwell B, Cooper M, Daniel M, et al. Overtreatment in the United States. PLoS One. 2017;12:e0181970.

5. Ruiz-Argüelles GJ. A new breed in the teaching of medicine: paid lecturers, trainers or speakers. Acta Haematol. 2016;135:191-2.

6. Ruiz-Argüelles GJ. Outpatient programs of myeloablative chemotherapy, autologous and allogeneic bone marrow transplantation. Haematologica. 2000;85:1233.

7. Ruiz-Argüelles GJ. Factors involved in the selection of treatment in patients with hematological malignancies. Acta Haematol. 2019;141:54. 